\title{
O FEDERALISMO NO BRASIL E NOS ESTADOS UNIDOS: UM ESTUDO COMPARADO NUMA ABORDAGEM HISTÓRICA
}

\author{
Marcelo Simões dos Reis
}

\begin{abstract}
RESUMO
O presente trabalho tem como objetivo explicar os processos históricos estruturantes das constituições brasileiras e norte-americanas. No desenvolvimento do tema busca-se estabelecer um paralelo entre os padrões constitucionais das duas nações de forma a evidenciar a importância dos fatos históricos na determinação das profundas diferenças entre os dois sistemas federativos. A forma como se deu o povoamento, as relações políticas no âmbito das localidades, o tratamento que a metrópole dispensava às suas colônias e as reações a esse tratamento são assuntos abordados com a finalidade de se esclarecer as razões que moldaram a natureza centralista do federalismo brasileiro e o caráter descentralizado do federalismo norte-americano.
\end{abstract}

Palavras-Chaves: Constituição; Federalismo no Brasil e Estados Unidos; Centralização; Descentralização.

\section{The Federalism in Brazil and the United States: a comparative study in a historical approach}

\begin{abstract}
The objective of the present work is to explain the historical developments which structured the American and Brazilian Constitutions. In the analysis it's been established a parallel between both constitutional patterns in order to evidentiate the importance of historical facts in the determination of differences between both federal systems. How the territory was populated, the political relationships in the localities, the treatment given by European nations to their colonies and their reactions to that treatment are examined subjects with the intention to clarify the reasons which tailored the centralist nature of the Brazilian federalism and the decentralized character of the American federalism.
\end{abstract}

Keywords: Constitution; Federalism in Brazil and United States; Centralization; Decentralization. 


\section{INTRODUÇÃO}

O presente estudo tem como objetivo traçar um esquema comparativo dos sistemas federalistas dos Estados Unidos e do Brasil. Para atingir um resultado satisfatório, a abordagem será predominantemente histórica, sem perder contato com os conceitos jurídicos que pertencem a qualquer estudo constitucional. De fato, os movimentos sociais percebidos nesses diferentes países ao longo da história, com seus processos políticos divergentes que moldaram as respectivas constituições, são de grande importância para sublinhar as diferenças e semelhanças encontradas nos dois sistemas.

Não é só relevante focar, como alguém poderia imaginar, nas atividades revolucionárias dos séculos XVIII e XIX, que encerraram a maior parte do domínio colonial no continente americano, mas também considerar o curso histórico anterior que afetou ambos os países. É claro que os medos e suspeitas, especialmente no caso dos Estados Unidos, levantados contra autoridades governamentais das metrópoles serão tomadas em conta. No entanto, situações subsequentes às declarações de independência deverão também ser examinadas. Por exemplo, a expansão para o Oeste, no caso dos Estados Unidos, impôs um desafio ao sistema federal, baseado originalmente na relação entre as treze colônias ${ }^{1}$.

No caso brasileiro, “medos e suspeitas” não necessariamente levaram a um governo federal como uma conseqüência imediata do controverso Grito do Ipiranga ${ }^{2}$. Apenas depois de 70 anos da independência, o Brasil tornou-se, então, uma república federativa. Isto não significa, todavia, que não há conexão entre o processo de descolonização e a adoção de uma federação tardia. Na verdade, os movimentos nativos pró-independência que precederam 1822, posteriormente adquirindo orientação republicana, exercem algum papel na compreensão do nascimento do federalismo brasileiro. Entretanto, não se pode esquecer

\footnotetext{
${ }^{1}$ James Madison, considerando a adição de novos territórios e a ameaça ao espírito federalista contido na Constituição de 1776, admitiu que "the arrangements that may be necessary for those angles and fractions of our territory which lie on our north-western frontier must be left to those whom further discoveries and experience will render more equal to the task" MADISON, James et alli, The Federalist Papers, Peguin, Londres, 1987, p. 143.

${ }^{2}$ WILLIAMSON, Edwin, The Penguin History of Latin America, Penguin, Londres, 1992, p. 230. Como é sabido, historiadores especulam que Dom Pedro I teria declarado a independência do Brasil sob influência de conselhos deixados por seu pai, Dom João VI.
} 
da influência estrangeira da própria constituição norte-americana na redação da primeira constituição republicana do Brasil, que inaugurou o período federalista.

Apesar da importância do período pós-independência, o trabalho também compreenderá uma visão detalhada das raízes coloniais. Como observado no período entre 1776, com a independência americana, e 1824, quando Bolívar e Sucre derrotaram os monarquistas no Peru ${ }^{3}$, a luta contra impérios coloniais e seu resultado, em diversos graus, foram influenciados pelo legado deixado pela estrutura política pré-existente.

É de se ressaltar, por exemplo, que o Brasil foi dividido em dois vice-reinados entre 1763 e $1774^{4}$. A continuidade desse modelo de administração poderia contribuir para a criação de dois Estados separados, talvez entrelaçados por uma frágil confederação. De fato, o uso de vice-reinados na América Hispânica influenciou em certa medida na diversidade dos atuais Estados soberanos, embora o sentimento bolivariano de unificação existisse $^{5}$. No caso do Brasil, contudo, como há de ser visto, essa não era a maneira tradicional do método português de centralização na administração colonial.

\section{Ocupação colonial}

\subsection{Estabelecimento das Treze Colônias}

Foi no século XVII que Europeus, principalmente os de origem inglesa, começaram a colonizar a banda oriental da América do Norte. Embora a maioria dos novos habitantes chegassem ao Novo Mundo de forma a escapar da opressão política e religiosa exercida por parte dos governos ou para aliviar uma situação econômica desesperadora ${ }^{6}$, a autoridade para ocupar as terras se originavam de mandatos concedidos pelos reis dos países natais, na sua maioria os próprios opressores. Nesta perspectiva, a emigração tinha um sentido de

\footnotetext{
${ }^{3}$ Idem, p. 228.

${ }^{4}$ Idem, p. 207.

${ }^{5}$ Idem, p. 231.

6 "Most European emigrants left their homelands to escape political oppresion, to seek the freedom to practice their religion, or for adventure and opportunities denied them at home" US STATE DEPARTMENT, Outline in American History, capítulo I, em http://usinfo.state.gov/products/pubs/history/toc.htm
} 
estabelecimento definitivo, na busca da edificação de um novo domicílio. A exploração dos recursos naturais era não mais que o instrumento para se alcançar um objetivo, a solidificação das primeiras colônias suportadas por um mínimo de desenvolvimento econômico. A preocupação em manter uma certa atividade lucrativa, então, é observada desde o princípio da vida colonial, principalmente com a produção de tabaco na Virgina ${ }^{7}$.

Uma característica importante desta frágil, mas florescente, economia era a ausência de um sistema efetivo de arrecadação de tributos. Às novas colônias faltava um governo que se encarregasse dessa tarefa e as cortes monárquicas da Europa não estavam apenas afastadas demais fisicamente, mas também desinteressadas. Contudo, alguns traços de autoridade oficial nas treze colônias britânicas começaram a aparecer sem a intervenção tanto da monarquia como da república que prevaleceram na Inglaterra do século XVII. Vários exemplos podem ilustrar tal cenário. Por volta do ano de 1620, um grupo de puritanos, que chegaram ao lugar que se conhece hoje como Massachussets, forjaram um pacto $^{8}$, o Mayflower Compact, documento que representava uma base de autoridade legitimada à parte dos governos europeus. Logo após, outros puritanos chegaram à região levando um título, que se referia à colônia de Massachussets Bay, concedido pelo rei Charles I e que investia os recém-chegados de poderes para se estabelecer no lugar. Por meio de uma corte geral, formada por membros da Igreja, eles implementaram um governo efetivo e isolado da influência monárquica. De fato, "the authority for the colony's government resided in Massachussets, not in England”.

Este padrão de relacionamento entre colonizadores e os governos britânicos foi mantido nas colônias de New Hampshire, Maine e Rhode Island, esta última formada pela dissidência da corte geral de Massachussets. O advento das novas colônias trouxe uma importante característica de sistemas políticos modernos, a separação entre igreja e governo.

\footnotetext{
7 "It was not long, however, before a development ocurred that revolutionized Virginia's economy. In 1612 John Rolfe began cross-breeding imported tobacco seed from the West Indies with native plants and produced a new variety that was pleasing to European taste. The first shipment of this tobacco reached London in 1614. Within a decade it had become Virginia's chief source of revenue" Idem, chapter I.

8 "Believing themselves outside the jurisdiction of any organized government, the men drafted a formal agreement to abide by "just and equal laws" drafted by leaders of their own choosing. This was the Mayflower Compact” Idem, chapter I.
} 
Em Maryland, em obediência ao mesmo padrão verificado acima, os colonos eram livres para se reunir e legislar sobre seus próprios problemas. Em verdade, mesmo a carta real que transferia autoridade à família Calvert afirmava que os detentores do título não poderiam legislar sem o consentimento dos proprietários de terras da colônia ${ }^{9}$. Em outras palavras, mesmo as leis do reino não pareciam ser aplicáveis, a não ser aquelas editadas com o consentimento dos proprietários estabelecidos na colônia.

Toda essa independência política com relação à metrópole emanava das grandes distâncias que aumentavam os custos da intervenção direta a níveis que inibiam a ação do governo britânico. Em adição a esse fator, a Inglaterra, durante o século em que a colonização iniciava na América do Norte, estava cercada de confrontações internas de ordem religiosa e política. Levando-se em conta essa conjuntura, dispender recursos com colônias em fase embrionária no extremo ocidente do Oceano Atlântico representava uma tarefa sem sentido prático. A falta de preocupação por parte da metrópole não renderia apenas a ausência de discussão sobre assuntos internos das colônias, mas também na deficiência da defesa contra outras nações européias. Isso resultou em alguma atenção dos colonos em relação à necessidade de organizar seus sistemas de defesa por si próprios ${ }^{10}$. Logo, é de se notar que a negligência britânica, em grande medida, ajudou a solidificar a independência política das treze colônias tanto no âmbito doméstico como no internacional.

\subsection{A Administração Portuguesa}

A colonização no Brasil iniciou-se quase um século mais cedo que na América do Norte. Embora os portugueses tivessem chegado em 1500, foi apenas trinta anos depois que a ocupação efetiva da terra começou. Ao contrário do caso da América Hispânica, a aparente falta de recursos naturais valiosos como ouro e prata, levaram à indiferença

\footnotetext{
9 "The royal charter granted to the Calvert family had a mixture of feudal and modern elements. On the one hand they had the power to create manorial estates. On the other, they could only make laws with the consent of freemen (property holders)" Idem, chapter I.

10 "The religious and civil conflict in England in the mid-17th century limited immigration, as well as the attention the mother country paid the fledgling American colonies. In part to provide for the defense measures England was neglecting, the Massachusetts Bay, Plymouth, Connecticut and New Haven colonies formed the New England Confederation in 1643. It was the European colonists' first attempt at regional unity" Idem, chapter I.
} 
temporária dos conquistadores ibéricos ${ }^{11}$. Com a exceção do pau-brasil, do qual se extraía uma tintura avermelhada própria para o tingimento de tecidos, nada no território era de interesse econômico imediato.

Nessa perspectiva, o mesmo cenário econômico desfavorável foi encontrado na América do Norte, no entanto, os objetivos das colônias estabelecidas ali eram de natureza diversa. Como os britânicos e outros europeus fugiam do Velho Continente com vistas a escapar da opressão política e religiosa, as aventuras dos colonos serviam como válvula de escape para os conflitos civis que permeavam as monarquias européias. Naturalmente, a autoridade real, ao mesmo tempo que tentava mitigar a pressão do confronto, esperava estender sua influência com a conquista de novos territórios. Entretanto, essa tarefa foi raramente implementada de fato como visto acima.

Na ausência de maiores conflitos civis, os Portugueses não se sentiram compelidos a deixar sua terra natal e arriscar suas vidas num empreendimento do outro lado do Atlântico sem expectativas de larga margem de lucratividade. O Brasil havia se tornado um mero destino para criminosos punidos com a pena de banimento e para comerciantes mal sucedidos $^{12}$. Além disso, dois documentos, a Bula Intercoetera e o Tratado de Tordesilhas, asseguravam a Portugal e Espanha, pelo menos do ponto de vista jurídico, a divisão do hemisfério ocidental entre eles ${ }^{13}$. Apesar de tais textos terem se originado de um frágil sistema jurídico internacional, as potências ibéricas foram beneficiadas por algumas décadas após a elaboração dos normativos, o que diminuía ainda mais a preocupação dos lusitanos em ocupar as terras ocidentais recém-descobertas.

\footnotetext{
11 "The first and most easily harvested fruits of the discoveries reverted in their entirety to the benefit of the Spaniards. The gold accumulated by long-settled civilizations on the Mexican meseta and Andean altiplano regions was the raison d'être of the Western Hemisphere and the main goal of the Europeans during the first stage of American history" FURTADO, Celso, The Economic Growth of Brazil, Greenwood Press, Westport, 1984, p. 2.

12 "For the next thirty years Portugal concentrated on India and the Far East, paying little attention to her modest colony in the west, which was settled by petty merchants, castaways and common delinquents known as degredados, who had been banished from Portugal to remote parts of the empire" WILLIAMSON, supra n 2, p. 168.

13 "In May 1493 Pope Alexander VI gave Spain all the land and islands discovered or to be discovered 100 leagues west of the Azores of Cape Verde Islands. Dom João II protested this concession, alleging that the pope had infringed on Portugal's rights. After this protest he was able to enter into negotiations with the neighboring monarchs, with whom a treaty was drawn up in Tordesillas. (...) The world was to be divided into two hemispheres: one belonging to Portugal, the other to Spain” ABREU, João Capistrano de, Chapters of Brazil’s Colonial History, 1500-1800, Oxford University Press, New York, 1997, p. 166.
} 
Contudo, logo outras potências marítimas estavam desafiando os direitos conferidos pela Bula Intercoetera ${ }^{14}$ aos primeiros navegadores. Portugal, a exemplo da Espanha, iniciou a ocupação no Brasil com foco na defesa do território. À exceção dos objetivos puramente militares, a coroa portuguesa não detinha recursos suficientes para dar fôlego a uma colonização efetiva. Dessa maneira, adotou o procedimento de conceder títulos de propriedade a particulares, os conhecidos capitães donatários, com o intuito de exercer o controle sobre o território colonial. Em comparação com o método britânico, as cartas de doação não eram endereçadas a líderes dissidentes que se estabeleceriam de fato nas novas terras, mas a indivíduos pertencentes a uma nobreza estabilizada na metrópole. Isso pode explicar porque as capitanias privadas ao longo da costa brasileira não resistiram ao teste do tempo. Os nobres portugueses sempre poderiam deixar a colônia para trás e retornar a metrópole, opção esta que não parecia viável para os colonos da América do Norte. Apenas duas das doze capitanias, Pernambuco e São Vicente, prosperaram, principalmente por conta do rápido sucesso com as plantações de cana-de-açúcar. É de se ressaltar, entretanto, que São Vicente foi diretamente governada pela coroa portuguesa.

Outra diferença, desta vez com relação ao conteúdo do título concedido pela metrópole, era a extensão dos poderes políticos transferidos ao beneficiário. Enquanto nas Treze Colônias os detentores dos títulos usufruíam de ampla liberdade para deliberar a respeito de suas próprias vidas, o que incluía o poder de legislar sem a intervenção de ordenanças vindas do reino, os capitães donatários estavam ainda vinculados ao controle monárquico. A relação entre o rei de Portugal e o capitão era de suserania e vassalagem, além de que a metrópole mantinha jurisdição tributária sobre a colônia ${ }^{15}$. Isso demonstra que as raízes políticas brasileiras estão associadas a uma tradição centralizadora que se perpetua para os futuros sistemas constitucionais. É evidente que esse primeiro sinal histórico não determina a forma federativa que o Brasil assumiu em diversas constituições posteriores à independência, mas influencia sobremaneira nessa caracterização.

\footnotetext{
14 "Spain and Portugal took for granted their rights to all the newly discovered lands, but those rights were disputed by the European nations with the greatest rate of commercial growth at the time: the Netherlands, France, and England" FURTADO, supra n 11, p. 4.

15 "The Crown nevertheless retained its prerogative of natural lordship over Brazil as a whole, setting out the constitutional rights of settlers in relation to the donatary-captain and reserving for itself the right to raise fiscal revenues from major commercial activities” WILLIAMSON, supra n 2, p. 168.
} 
A mesma análise histórica é de ser aprofundada quando se leva em consideração a solução real para o problema das fracassadas capitanias. Tomando como início o ano de 1549, o Brasil foi administrado por governadores-gerais, nomeados pelo rei de Portugal e cuja jurisdição se estendia sobre todas as capitanias ${ }^{16}$. Já naquele tempo, os brasileiros vieram a conhecer o que seria sua primeira capital, a sede do governo-geral, a cidade de Salvador. Naturalmente, na América do Norte, nada pode ser comparado a esse marco da história colonial.

\section{Desenvolvimento das Relações Coloniais e Independência}

\subsection{Tentativa Britânica de Controlar suas Colônias e o Clímax de 1776}

Como já foi anotado, o pouco rígido sistema colonial britânico criou o ambiente propício para o surgimento de um senso de auto-governo nos domínios ultramarinos. O mandato atribuído aos colonos era amplo e cobria até mesmo autonomia legislativa ${ }^{17}$, contudo, o rei tinha expectativas de reter prerrogativas para o futuro, principalmente quando os conflitos internos e os inimigos externos não fossem mais um obstáculo para a administração do Império. De fato, nada nas cartas de concessão continha uma transferência de poder soberano aos colonos. Entretanto, pela operação do costume, a recorrente negligência no exercício do privilégio $^{18}$ inevitavelmente tornou obsoleto o controle da coroa britânica. Sem que a monarquia inglesa pudesse perceber, a legitimidade

\footnotetext{
16 "Once more the Crown had to intervene in order to secure control of Brazil, creating the post of governorgeneral to oversee all the captaincies” idem, p. 168.

17 "In most instances, the king, in making future grants, provided in the charter that the free men of the colony should have a voice in legislation affecting them. Thus, charters awarded to the Calverts in Maryland, William Penn in Pennsylvania, the proprietors in North and South Carolina and the proprietors in New Jersey specified that legislation should be enacted with "the consent of the freemen." US STATE DEPARTMENT, supra n 6, chapter 2.

${ }^{18}$ A good indication of the British tolerance is found in the Plymouth settlement: "although there was no legal basis for the Pilgrims to establish a system of self-government, the action was not contested and, under the compact, the Plymouth settlers were able for many years to conduct their own affairs without outside interference" Idem, chapter 2.
} 
gradualmente passou das mãos da autoridade central em Buckingham para diferentes legislaturas estabelecidas pela porção oriental da América do Norte ${ }^{19}$.

Ocasionalmente, durante os intervalos das guerras, que castigaram a Inglaterra nos séculos XVI e XVII, a coroa tentou exercer sua deficiente autoridade sobre os colonos com o envio de governadores aos domínios extraterritoriais. Em contraste com a experiência brasileira, tais administradores tiveram de experimentar, em muitos casos, o amargor da postura confrontacional apresentada pelos norte-americanos ${ }^{20}$.

Além disso, seguindo o mesmo passo das declinantes potências coloniais de Portugal e Espanha, a Inglaterra ansiava por implementar certas medidas de natureza mercantilista $^{21}$, que prevaleceram na economia internacional no início da era moderna. O chamado pacto colonial foi um dos pilares do sistema e compreendia a regra do monopólio da metrópole no comércio com a colônia. Numa interpretação radical do princípio, mesmo o comércio interno à colônia deveria ser controlado exclusivamente pela metrópole ${ }^{22}$.

Nesse contexto, o escopo dos conflitos anglo-americanos estava para ser dilatado com a vitória britânica contra a França na Guerra dos Sete Anos. O fim da disputa resultou na entrega de possessões francesas na América do Norte à Inglaterra e, a paz que se iniciou em 1763, paradoxalmente levou a Coroa a assumir o ônus de manter o império ${ }^{23}$. Antes da solidificação do poder inglês, essa tarefa estava essencialmente relacionada à defesa contra agressores externos, e talvez pudesse ser realizada em associação com os colonos, evitando-

19 "Resistance to imperial authority centered in the colonial legislatures. By the 1750s the assemblies had become accustomed to levying taxes, making appropriations, approving appointments, and passing laws for their respective colonies” BRINKLEY, Alan, The Unfinished Nation, McGraw-Hill, New York, 1993, p. 86.

${ }^{20}$ In order to illustrate the situation it is valuable to mention an event registered by Kammen: "In 1691 King William III appointed Benjamin Fletcher to be governor of New York and also commander in chief of Connecticut's militia. When Fletcher reached the colonies in 1692, however, he found that Connecticut's assembly vigorously rejected his right to control their militia. Consequently, late in the crisp autumn of 1693, Fletcher hied himself to Hartford and caused his royal commission to be read publicly. The Yankee governor, Robert Treat, listened with disdain, then ordered the drums to be beaten in defiance. When Fletcher threatened Treat with imperial retribution, Connecticut's elected executive stepped forward, and with his hand on the hilt of his sword, declaimed: 'If my drummers are again interrupted, I'll make sunlight shine through you. We deny and defy your authority'.” KAMMEN, Michael, People of Paradox, Oxford University Press, New York, 1980.

21 "In the 1670s, the Lords of Trade and Plantations, a royal committee established to enforce the mercantile system on the colonies, moved to annul the Massachusetts Bay charter, because the colony was resisting the government's economic policy"US STATE DEPARTMENT, supra n 6, Chapter 2.

${ }^{22}$ See infra, note 62.

23 "Having triumphed over France, Britain was now compelled to face a problem that it had hitherto neglected -- the governance of its empire. It was essential that London organize its now vast possessions to facilitate defense, reconcile the divergent interests of different areas and peoples, and distribute more evenly the cost of imperial administration" Supra n 6, Chapter 2. 
se a interferência em assuntos domésticos. No entanto, depois que a ameaça comum francesa foi eliminada com a rendição de Quebec e outros territórios, perspectivas divergentes nasciam a partir do trato de questões internas. A questão dos índios, nativos norte-americanos, mostrou-se como um ponto de atrito entre os colonos e os governadores mandados de fora. De um lado, pioneiros, ávidos por desbravar o oeste do continente, consideravam os nativos como inimigos que precisavam ser expulsos. Por outro, a abordagem tradicional britânica em que o status quo deveria ser mantido para que conflito desnecessário fosse evitado ${ }^{24}$.

Além das diferenças com relação à problemática indígena, a coroa estava planejando impor tributos às colônias para amenizar os gastos com defesa, transformando o cenário geral de liberdade usufruída por mais de um século ${ }^{25}$. Em 1764, Grenville, Primeiro Ministro de George III, pôs em prática o plano de obter receitas públicas dos norteamericanos. A Lei do Açúcar (Sugar Act) havia sido editada, afetando alguns comerciantes locais no tocante a tarifas de importação. Essa interferência atingiu apenas uma porção da sociedade colonial, aquela dos negociadores de uma determinada mercadoria, não havendo grande resistência. No ano que se seguiu, entretanto, a coroa viria a tomar medidas mais amplas. Com o objetivo de coletar tributos de todos os documentos impressos, de jornais a atos oficiais, a Lei do Selo (Stamp Act), sem o consentimento das legislaturas coloniais, causou grande revolta na sociedade norte-americana como um todo e, claro, nos seus representantes eleitos por um sistema de legitimação de longa data ${ }^{26}$. Depois que um boicote contra comerciantes britânicos, planejado por uma assembléia com a participação de delegados de nove colônias, foi posto em prática efetivamente, a Lei do Açúcar e a Lei do Selo foram revogadas. Apesar disso, os parlamentares em Londres declarou que toda

\footnotetext{
24 "Linked to the military question, as I have indicated, was that of the Indians and the Western lands. The imperial government took the view that unless there was to be endemic, expensive and bloody war on the frontier of settlement, pledges made to the Indians had better be kept, and all transfers of land from red men to white had better be made with due legal propriety, including fair payment of the Indians" BROGAN, Hugh, Longman History of the United States of America, Longman, New York, 1986, p. 122

25 "It was easy to decide that the British taxpayer, already the most heavily mulcted in the Western World, should not be further burdened. (...) In the view of Grenville, and indeed of most people who thought about the matter, it was high time that the Americans assumed a share of the burden of their own defence" Idem, p. 114-115.

26 "In Massachusetts at about the same time, James Otis persuaded his fellow members of the colonial assembly to call an intercolonial congress to take action against the new tax. And in October 1765, the Stamp Act Congress, as it was called, met in New York with delegates from nine colonies and petitioned the king and Parliament. Their petition denied that the colonies could rightfully be taxed except through their own provincial assemblies” BRINKLEY, supra n 19, p. 99.
} 
legislação aprovada por eles vincularia as colônias em todos os casos, incluindo a imposição de tributos. Com isso, o Parlamento britânico tentava deixar uma passagem que possibilitaria intervenções futuras, mas o sucesso do boicote norte-americano havia marcado a experiência colonial de maneira indelével. O mérito da assembléia mencionada acima é que, depois de duzentos anos de colonização, um acordo inter-colonial pôde ser finalmente traçado e implementado ${ }^{27}$. Isso viabilizou o ideário em torno das possibilidades de uma autoridade central nas Treze Colônias que posteriormente moldariam o governo federal independente.

Não era surpresa que, após a vitória política norte-americana, um sentimento de repúdio contra o fenômeno de "tributação sem representação” crescesse. Para os colonos, o governo da metrópole estava tentando não só suprimir as liberdades adquiridas pelos mandatos e negligências reais como também restringir tais liberdades sem uma base de reciprocidade. Não havendo representação na câmara baixa do parlamento britânico, a imposição de obrigações e de taxas sobre as atividades coloniais era um exercício impossível levando-se em conta o dissenso que tomaria as assembléias locais.

No tocante às tarifas externas, contudo, os sentimentos norte-americanos contra a “tributação sem representação” tendiam a arrefecer já que esses tributos estavam mais relacionados à regulação do comércio exterior do que com o cotidiano dos indivíduos comuns. Dessa forma, o próximo passo britânico foi enfocar na importação de mercadorias, esperando que a repercussão fosse limitada como no caso da Lei do Açúcar. Mais uma vez, para o infortúnio da monarquia, os habitantes da América do Norte se uniram contra as novas tarifas alfandegárias ${ }^{28}$. As manifestações seguintes escalaram para uma situação insustentável mesmo quando a tarifa teve seu escopo reduzido à importação de chá apenas, levando ao clímax histórico representado pelo evento da Boston Tea Party. Imediatamente após a Inglaterra ter retaliado a colônia de Massachussets, todas as Treze Colônias, com a

\footnotetext{
27 "For the first time an inter-colonial body met whose authority was accepted, not rejected, by all the colonies” BROGAN, supra n 24, p. 134.

28 "New taxes (known as the Townshend Duties) were levied on various goods imported to the colonies from England - lead, paint, paper, and tea. Townshend reasoned that since these were taxes purely on 'external' transactions (imports from overseas) as opposed to the internal transactions the Stamp Act had taxed, the colonists could not object. But the distinction between external and internal taxation meant little to the colonists. The purpose of new duties, they claimed, was the same as that of the Stamp Act: to raise revenue from the colonists without their consent” BRINKLEY, supra n 19, p. 100-101.
} 
exceção da Georgia, demonstraram seu apoio em uníssono aos rebeldes de Boston $^{29}$, assim estabelecendo-se o Primeiro Congresso Continental. O cenário, apesar de haver facções leais à metrópole, estava preparado para a independência.

Antes de se concluir este tópico, é relevante apontar duas decisões tomadas no congresso citado acima. Em primeiro lugar, os delegados desautorizaram quaisquer planos da metrópole no sentido de formar uma união colonial. Para alguns autores, ao tomar essa resolução, os membros do congresso rejeitavam especificamente a autoridade britânica, mas o estado de independência política entre as colônias poderia levar a se acreditar que a rejeição era contra qualquer autoridade central. No entanto, em outra decisão, os representantes estabeleceram uma associação continental cujo mandato incluía a supervisão dos boicotes comerciais acordados contra a Inglaterra. Embora a jurisdição de tal associação fosse minúscula, a ação coletiva norte-americana indicava uma certa medida de governo supra-colonial ${ }^{30}$.

Antes da guerra de independência ter começado, a declaração respectiva já mostrava traços da federação que, mais tarde, passaria a existir. O termo United States não passa desapercebido aos olhos do leitor no último parágrafo: "We, therefore, the representatives of United States of America, in general Congress assembled, (...), solemnly publish and declare, that these united colonies are, and of right ought to be, free and independent states. (...)[And] have full power to levy war, conclude peace, contract alliances, establish commerce, and to do all other acts and things which independent states may of right do". Contrários a um governo unificado, entretanto, as palavras free e independent são mais incisivas ainda do que o sentido de união representado por outros vocábulos. A confrontação entre as liberdades coloniais e a autoridade central, então, guiou a gestação do embrião da federação.

\subsection{A Contínua Intervenção Portuguesa e uma Frágil Independência}

\footnotetext{
29 "Instead of subduing and isolating Massachusetts as Parliament intended, these acts rallied its sister colonies to its aid" US STATE DEPARTMENT, supra n 6, chapter 3.

${ }^{30}$ Brinkley lists the five major decisions adopted at the Congress. The ones that were focused in this work are thus referred: “(...) they rejected a plan for a colonial union under British authority” and “(...) they agreed to a series of boycotts that they hoped would stop all trade with Great Britain, and they formed a "Continental Association' to see that these agreements were enforced” BRINKLEY, supra n 19, p. 109.
} 
Na vertente contrária da Inglaterra, Portugal manteve uma forte presença governamental em sua colônia. O fracasso do modelo privado de colonização no Brasil, somada à bem sucedida busca desse objetivo pela coroa portuguesa, não significava, contudo, que a ordem entre os colonos era fácil de se manter em todos os casos. O crescimento de uma elite agrária, vinculada principalmente à exportação de açúcar, criou um núcleo de poder genuinamente brasileiro. De quando em quando, o conflito parecia evidente entre a aristocracia rural colonial e o monopólio comercial estabelecido em favor da metrópole. O exemplo mais incisivo foi a Guerra dos Mascates de 1710. Pesadamente endividados com os comerciantes portugueses sediados em Recife, conhecidos como Mascates, os fazendeiros de Olinda decidiram tomar o controle da cidade vizinha. Um ano depois, entretanto, o novo enviado à capitania de Pernambuco dirimiu a disputa. Uma frágil semente por independência e repúdio à autoridade externa havia sido plantada ${ }^{31}$, mas nunca desenvolveu tão vigorosamente como nas Treze Colônias.

Uma das fundações da dominação colonial em operação no Brasil era a implementação efetiva de medidas coerentes com o sistema mercantilista. As políticas do rei estavam geralmente em alinhamento com os interesses da elite rural. No entanto, os monopólios impediam que os colonos de comerciar com outras nações européias, à exceção de algum contrabando. O enorme superávit provido pela monocultura de exportação $^{32}$ serviu para diluir o primeiro espírito de revolta. Além disso, a elite do açúcar se aproveitava de diversos benefícios como a concessão de títulos nobiliárquicos e tributação privilegiada, um prêmio que não era igualmente distribuído pelas demais atividades $^{33}$. Naturalmente, com o declínio da rentabilidade em decorrência da agressiva concorrência holandesa nas ilhas do Caribe, a supracitada Guerra dos Mascates deflagrou, mas, ao contrário da histórica evolução na América do Norte, os agora empobrecidos colonos já estavam acostumados à presença de uma autoridade externa. Quando o comando

31 "Indeed, even as early as the 1710-1711 disturbance, some planters in their hostile reaction to the outsiders mentioned vaguely the possibility of creating some independent republic modeled on that of Venice" BURNS, E. Bradford, A History of Brazil, Columbia University Press, New York, 1970, p. 73.

32 "The total value of the sugar exported in a favorable year probably amounted to about $£ 2.5$ million. (...) Taking into account the fact that the European population was not more than 30,000 persons, the small sugar colony must have been exceptionally rich" FURTADO, supra n 11, p. 46.

33 "Later, special concessions were made - such as tax exemptions, guarantees against court attachment of production facilities, honorary recognitions, titles, and so on - to those prepared to install sugar mills" Idem, p. 43. 
da coroa foi ouvido, com a nomeação de um novo administrador para a capitania, nenhum protesto pôde ser realizado.

De fato, a vida colonial estava infiltrada pela interferência monárquica. Não somente a presença de tropas era recorrente, mas também tributos eram coletados de diversas maneiras ${ }^{34}$. Mesmo na questão da expansão para o interior do continente, seguindo o exemplo da Inglaterra, Portugal se manifestou, proibindo a penetração no ocidente no momento da chegada do primeiro governador-geral sob a alegação de evitar conflitos com índios hostis ${ }^{35}$. Obviamente, essa política foi revertida com a percepção de que ouro poderia ser achado no interior ${ }^{36}$, e, com o consentimento da coroa, o território brasileiro experimentou sua primeira expansão.

Uma classe burguesa nativa, cujo ambiente fosse favorável ao florescimento das idéias liberais do Iluminismo, mal havia sido formada, levando-se em consideração que promissores mercadores preferiam manter-se vinculados ao setor exportador. Dessa forma, seu domicílio comumente permanecia na Europa e seu interesse na política local muito escasso. Considerando que o governo da metrópole havia obstruído tentativas de diversificação da economia ${ }^{37}$, engajamento no comércio interno seria realmente uma empresa desanimadora. Desse quadro de apatia política pode se explicar as esporádicas tentativas de emancipar o comércio que tomaram lugar, demonstrando o parco esforço nativo em ampliar as transações comerciais com outros países europeus. Em 1684, por exemplo, um rico proprietário de terras, Manuel Beckman, num esforço de liberar os colonos dos grilhões do sistema mercantilista e subjugar a Companhia do Maranhão, organizou uma revolta armada, mas foi prontamente derrotado ${ }^{38}$.

\footnotetext{
34 "Taxes, many and varied, put special strains on the economy. There were taxes on agricultural mineral, and pastoral products, known as the dízimo, or tithe, and the quinto, or fifth, levied on mineral resources. (...) The Crown taxed both the internal and external commerce of its colony” BURNS, supra n 31, p. 70.

35 "The instructions to Governor-General Tomé de Sousa ordered him to prohibit expansion into the interior without special permission" Idem, p. 44.

36 "From time to time some timid exploration filtered into the interior. Those entradas resulted from a curiosity to learn what the hinterland might offer and from a hope of discovering gold and other precious metals" Idem, p. 44.

37 "Fearful that the colony might relax its efforts to produce the raw products most in demand in Europe, the royal officials kept a sharp eye peeled for unnecessary diversification of the economy. In the best mercantilistic manner, Brazil could produce nothing which Portugal already produced or could furnish" Idem, p. 71.

38 "In Maranhão, in 1684, Manuel Beckman, a wealthy landowner, led an armed revolt to protest against the detested Companhia do Maranhão (...). The following year a new governor arrived who captured, tried, and hanged Beckman” Idem, p. 72.
} 
Para entender melhor a situação, necessário se faz uma comparação entre as assembléias formadas nas Treze Colônias e os conselhos municipais no Brasil. Ao contrário dos representantes do hemisfério norte, os membros desses conselhos eram geralmente mal preparados. Não houve preocupação em se criar universidades, tendência reversa da Nova Inglaterra com Harvard e Yale. Apenas no primeiro quartel do século XIX os primeiros cursos superiores foram estabelecidos, exigindo-se daqueles que almejassem uma educação de nível superior uma longa estada em Coimbra. Desnecessário dizer, a representação nos conselhos era largamente formada pela aristocracia rural, que conseguiu permanecer à frente do poder local mesmo depois que o ciclo do açúcar se encerrava ${ }^{39}$. Provavelmente, não havia grupos contrários que pudessem reclamar o poder político dos fazendeiros no nível regional. No tocante às leis do império português, apesar do conflito com agentes da coroa não ser inteiramente ausente ${ }^{40}$, a aplicação das normas nunca se traduziu numa ação efetiva e coordenada como aconteceu no congresso continental norte-americano. A medida de maior peso tomada pelos conselhos municipais foi expulsar os jesuítas e autoridades da metrópole que estavam tentando proibir a escravização de índios ${ }^{41}$. No que afetava o sistema mercantilista e seus monopólios, algumas petições foram enviadas ao rei, mas jamais positivamente respondidas. No entanto, por quase três séculos, as assembléias brasileiras não trataram de uma questão que parece ser de vital importância quando disputas políticas estão em cena: a tributação. Ao se iniciar um novo ciclo econômico para o Brasil, a mineração de ouro, essa persistente temática iria finalmente criar um foco de conflito no Brasil.

Durante meados do século XVIII, com a descoberta de minas de ouro com destaque para Minas Gerais, Portugal havia imposto um tributo de 20\% em todas as extrações, o chamado “quinto”. Como a produção declinava e a metrópole suspeitava de que a queda era efeito de sonegação, a coroa converteu a alíquota percentual num montante fixo que deveria ser remetido a Portugal anualmente. Não inesperadamente, as vilas mineiras se viram altamente endividadas com o tesouro real na década de 1780. Logo, atos de coleta forçada

\footnotetext{
${ }^{39}$ The War of Mascates shows us this fact as the declining aristocracy still held political power in Olinda.

40 "At times the senados dared to challenge the Crown itself. The inauguration of the convoy system in the seventeenth century excited the wrath of the senados of both Bahia and Rio de Janeiro" Idem, p. 85.

41 "One of the bitterest struggles was over the Indians. The senados of Belém, São Luís, Rio de Janeiro, and São Paulo, to mention only the most vitriolic, were locked in battle for decades with crown officials over the Indian question” Idem, p. 85.
} 
estavam se perfazendo por toda a região mineira, desestabilizando os residentes. Além disso, a tradicional interferência da metrópole controlava a produção de barras de ouro ${ }^{42}$, numa tentativa de deter o mercado clandestino. Um plano para a revolta, sob o ideário liberal e inspirado na Revolução Americana, foi projetado, mas a conhecida Inconfidência Mineira foi precocemente desmantelada em 1789. A partir dela, no entanto, uma série de revoltas se seguiu ${ }^{43}$.

Todos os movimentos revoltosos foram debelados com a conhecida eficiência portuguesa, que provavelmente estava relacionada à fraqueza dos líderes políticos coloniais. Entretanto, a independência era só uma questão de tempo. A chegada da família real ao Rio de Janeiro em 1808, fugida do ódio napoleônico, havia trazido, por acaso, alguns dos privilégios que os colonos timidamente reivindicavam. O comércio exterior foi aberto a todas as nações amigas, com algum favoritismo direcionado à Inglaterra, e o Brasil foi elevado à categoria de Reino Unido com Portugal e Algarve. Alguns anos depois, contudo, uma assembléia liberal baseada em Lisboa, formada logo após a derrota de Napoleão, exigiu o retorno de Dom João VI à Europa. Rumores corriam a respeito da tendência dos liberais portugueses em restaurar o antigo regime colonial, incluindo práticas monopolísticas, revoltaram os brasileiros ${ }^{44}$. Com a sua partida para a Europa, o rei deixou seu primogênito, Pedro, cuja mente havia sido preparada pelo conselho paterno para assumir um papel de liderança na iminente independência do Brasil ${ }^{45}$. Assim, a dinastia dos Bragança haveria de assegurar a coroa tanto em Portugal como no Brasil. Enquanto repúblicas surgiam por toda a América, incluindo a de origem hispânica, com o advento da independência, a monarquia prevaleceu na ex-colônia portuguesa. Ao que parece, mesmo

\footnotetext{
42 "The Laws of the Kingdom (Ordenações do Reino) registered the mines as royal property.(...) It was against the law to open new trails, to open new mills, to carry gold dust or gold coins. People could not be goldsmiths" ABREU, supra n 13, p. 133-134.

43 "(...) these influences blended with a growing pride in Brazil, an increased awareness of the U.S. and French republican experiences, and economic dissatisfaction. Hence the Inconfidência Mineira was followed by chain-reaction conspiracies in Rio de Janeiro (1794), Bahia (1798), and Pernambuco (1801)" SCHNEIDER, Ronald M., Order and Progress: a political history of Brazil, Westview Press, Boulder, 1991, p. 32.

44 "The liberal government proposed to cancel the political equality of Brazil with Portugal and the freedom of trade which the king had decreed for Brazil when he had first arrived in Rio. This the Brazilians would not countenance" WILLIAMSON, supra n 2, p. 230.

45 "Thus when the king was required to return to Lisbon in April 1821, he advised his 22-year-old son, Pedro, staying behind as prince regent, to place himself at the head of the movement for independence should it appear to be getting out of control" SCHNEIDER, supra n 43, p. 33.
} 
quando os brasileiros tinham de dar um passo adiante, dado o sentimento generalizado de revolta, uma fonte de poder central era fundamental.

\section{Rumo a uma Federação}

\subsection{Busca de uma Autoridade Central}

Libertos de qualquer dependência formal com a Grã-Bretanha, os novos Estados da América do Norte, politicamente agregados por uma confederação instável, estavam fortemente resignados em manter suas liberdades, como a declaração de independência aparenta externar ${ }^{46}$. Já se demonstrou acima que os americanos já tinham tradição em repelir autoridades governamentais externas quando houvesse ameaça à autonomia das assembléias coloniais. Tamanha resistência, entretanto, não estava apenas restrita a autoridades estrangeiras. Estendeu-se a qualquer forma de poder centralizador que pudesse por à perigo a autonomia dos Estados individuais. De fato, este sentimento de rejeição podia ser observado mesmo quando a unidade colonial pareceu primordial para o trato de problemas comuns. O mais ilustrativo exemplo desse fenômeno ocorreu em 1754 com a recusa do plano Albany proposto por Benjamin Franklin ${ }^{47}$. Realmente, uma confederação só veio a surgir por conta da estrita necessidade de um exército unificado para levar a guerra contra a Inglaterra adiante. Após a vitória, essa aliança de laços soltos não seria suficiente para conduzir certas questões que haviam se tornado verdadeiramente nacionais a todos os novos Estados independentes. Alexander Hamilton, um federalista influente, realçou a existência de rios, ancestrais, língua e, principalmente, princípios de governo

\footnotetext{
46 "Philosophically, the Declaration was remarkable for its assertion that certain rights, which it called "unalienable rights" - including life, liberty, and the pursuit of happiness - could not be abridged by governments" LOWI, J. Lowi, and GINSBERG, Benjamin, American Government, W.W. Norton, $7^{\text {th }}$ edition, 2002, p. 17.

47 "Still, the colonists were reluctant to cooperate even when, in 1754, they faced a common threat from their old rivals, the French, and France's Indian allies. (...) The delegates tentatively approved a plan offered by Benjamin Franklin to set up a 'general government' in America to manage relations with the Indians on behalf of all the colonies. War with the French and Indians was already beginning when this Albany Plan was presented to the colonial assemblies. None approved it” BRINKLEY, supra n 19, p. 86-87.
} 
comuns a todos os Estados Unidos. Era inegável que um sentimento nacional permeava as ex-colônias ${ }^{48}$.

No entanto, os Estados individuais eram ainda predominantes na política nacional conforme os Artigos da Confederação. Um exemplo desse fato é que todos os recursos confederados dependiam de contribuições voluntárias realizadas pelos Estados ${ }^{49}$. Algumas diferenças irreconciliáveis entre essas emergentes repúblicas autônomas marcou o período até a aprovação da Constituição de 1789. Muitas delas cunhavam sua própria moeda, mantinham seus próprios exércitos, entravam em relações diplomáticas e regulavam o comércio entre os Estados e com o exterior. Também é notável a existência de disputas territoriais nas terras ocidentais, criando preocupação em torno de um conflito catastrófico entre as ex-colônias. Não é de se surpreender que tal estado belicoso levantaria o desejo dos mais preocupados em resolver as discrepâncias com um governo central poderoso ${ }^{50}$.

Além do mais, a radicalização das idéias liberais defendidas por Locke e Rousseau, em que se interpretava que o povo seria o único legitimado para exercer o poder, ocasionou a formação de governos fracos e instáveis enquanto que a "política da liberdade" conferiu aos indivíduos poderes exagerados para fiscalizar os legislativos estaduais. Em sua introdução ao "Federalista”, Isaack Kramnick registra que, em Rhode Island e Connecticut, eleições eram realizadas a cada seis meses enquanto que havia se tornado lugar comum em muitos Estados a necessidade de referendo popular direto para que emendas às respectivas constituições pudessem ser aprovadas. Adicionando-se a isso a crise da dívida subsequente à Guerra de Independência, o resultado político era insustentável. Leis que concediam relaxamento de débitos e revertiam decisões judiciais contra devedores ameaçava os direitos de propriedade, e estavam se tornando regulares em várias legislaturas. E, mesmo quando os Executivos estaduais tentavam garantir os direitos dos credores, a rebelião

\footnotetext{
48 "This country and this people seem to have been made for each other, and it appears as if it was the design of Providence that an inheritance so proper and convenient for a band of brethren, united to each other by the strongest ties, should never be split into a number of unsocial, jealous, and alien sovereignties" MADISON, James, et alli, supra n 1, p. 91.

49 "Crucially, no mandatory power to raise taxes was established. Instead, Congress had to rely on voluntary contributions from the state legislatures" McKAY, David, Essentials of American Government, Westview Press, Boulder, 2000, p. 50.

50 "Neighboring nations are naturally enemies of each other, unless their common weakness forces them to league in a Confederated republic, and their constitution prevents the differences that neighborhood occasions” MADISON, et alli, supra n 2, p. 108.
} 
popular estava à vista. A revolta de Shay em Massachussets é a representação de tal cenário social fragmentado ${ }^{51}$.

Mercadores e proprietários de terra, os membros chave da elite americana e os mais afetados pelas tendências extremistas, tendiam a favor da instituição de um governo central munido de recursos perenes, sendo a Convenção da Filadélfia convocada para revisar os Artigos da Confederação. Muito cedo, o plano original foi alterado e a redação de uma constituição federalista tornou-se o objetivo primário. Entretanto, alguns desafios estavam por serem vencidos, uma vez que as diferenças entre os Estados constituíam um ponto pivotal nas discussões.

Embora os delegados estivessem resolvidos a introduzir a divisão dos três poderes, em tributo à doutrina de Montesquieu, o maior problema estava no legislativo. Representação num congresso nacional seria um empecilho se o princípio da proporcionalidade fosse adotado. Naturalmente, o número de habitantes em cada Estado não era o mesmo. Dessa forma, a adoção de um mero sistema proporcional submeteria os Estados menores à dominação dos mais populosos. Para resolver tal desequilíbrio, o chamado “Great Compromise”, em que um Senado garantiria participação igualitária aos Estados nas questões legislativas, foi alcançado ${ }^{52}$. Apesar da boa aceitação dessa idéia de engenharia política, mais um problema relacionado à população necessitava ser tratado.

Como acordado entre os delegados, a câmara baixa do novo sistema federal bicameral, a Câmara dos Representantes, teria seus assentos distribuídos conforme o princípio da proporcionalidade. Entretanto, os Estados agrários do sul ainda utilizavam mão-de-obra escrava, sendo que os habitantes não-livres contabilizavam uma grande porção da população total. A aristocracia rural representada na Convenção, naturalmente, não avalizava a idéia de conceder o direito de voto aos escravos, mas demandava que eles fossem considerados no cálculo das cadeiras disponíveis na câmara baixa. Embora um ponto complicado de contraste houvesse surgido entre dois grupos de Estados, o chamado “Three-fifths Compromise” foi aceito com o intuito de levar adiante o ideal federalista. Sob

\footnotetext{
51 “(...) an armed revolt against a duly constituted republican government had come dangerously close to succeeding; that property was in danger; and that nowhere in America was there sufficient force to defeat another such challenge, either internal or external” BROGAN, supra n 24, p. 197.

${ }^{52}$ LOWI, GINSBERG, supra n 46, p. 20.
} 
esse compromisso, um escravo, para efeitos do cálculo do número de deputados, valeria o equivalente a três quintos de uma pessoa livre ${ }^{53}$.

Resolvidos, ao menos temporariamente, os antagonismos relacionados à participação dos Estados no nível federal, os delegados se dedicaram à distribuição de poder entre governo federal e governos estaduais. A competência legislativa, logo, estava por ser delineada com base na doutrina dos poderes expressos em que o Congresso Nacional poderia editar leis apenas com relação às questões especificamente listadas na Constituição (Artigo 1, Seção 8). Os demais temas entrariam no escopo dos Estados ou em sua ação coletiva. Contudo, aqueles que favoreciam um governo central forte, temendo que uma lista inflexível de competências limitaria a habilidade do centro em manobrar em situações imprevisíveis, defenderam a inclusão de uma cláusula apropriada e necessária justamente no fecho do rol dos poderes expressos ${ }^{54}$.

Definida a extensão da autoridade que cabia à esfera federal e estadual, outro tema sensível permanecia. A aplicação direta de leis por um Poder Executivo também federal seria não menos que ultrajante para os vários Estados membros da já quase formada federação. Para contornar o problema, a redação escolhida para o Artigo VI, que exterioriza a cláusula da supremacia, considerava que a legislação federal era a lei suprema do país. Concebida dessa maneira, o imediato uso de forças federais no território dos Estados seria desnecessário. Preocupações individuais com casos relacionados à legislação federal seriam levadas aos tribunais cujos juízes teriam de respeitar a lei aplicável, fosse ela estadual ou federal $^{55}$. A intervenção federal, então, só poderia tomar lugar no caso de consentimento ou extrema desobediência ao cumprimento de decisão judicial emitida por um tribunal federal $^{56}$.

Finalmente, o procedimento de emenda à Constituição demonstra quanto os Estados barganharam pela manutenção do seu poder político. Como eles estavam renunciando à sua

\footnotetext{
${ }^{53}$ Idem, p. 20-21.

${ }^{54}$ Idem, p. 22.

55 "Finally, the Convention faced the most important problem of all: how should the powers given to the new government be enforced? Under the Articles of Confederation, the national government had possessed -- on paper -- significant powers, which, in practice, had come to naught, for the states paid no attention to them. What was to save the new government from the same fate? At the outset, most delegates furnished a single answer -- the use of force. But it was quickly seen that the application of force upon the states would destroy the Union. The decision was that the government should not act upon the states but upon the people within the states, and should legislate for and upon all the individual residents of the country" US STATE OF DEPARTMENT, supra n 6, chapter 4 .
} 
autonomia para a criação de uma constituição comum, qualquer alteração futura teria de ser logicamente submetida à apreciação desses Estados. Não era necessário o consentimento unânime de cada ente federado, pois as mudanças seriam quase impossíveis, mas sim três quartos de todos os Estados. Apesar da flexibilização do instituto da emenda, ainda sim mudanças constitucionais se provaram extremamente difíceis de serem realizadas. De acordo com Lowis e Ginsberg, apenas 27 de onze mil propostas de emenda puderam ser aprovadas. Entretanto, é certo que evolução constitucional, após a sua ratificação em 1789, não se deu apenas com a modificação do texto escrito do documento original. Estando o campo do abstrato pronto para as várias interações entre autoridades centrais e locais, uma relação dialética entre a doutrina dos poderes expressos e a cláusula “elástica”, como veio a ser conhecida, predominaria na evolução do federalismo norte-americano.

\subsection{Em busca da descentralização}

Proclamada a independência de cima para baixo, sem que forças regionais oriundas das capitanias se manifestassem no processo, é sedutor chegar à conclusão de que a autonomia local era inexistente. Mesmo a presença coerciva contínua dos portugueses não pôde impedir o advento de uma consciência nativa nas diferentes regiões do Brasil. De fato, Pernambuco chegou a implementar o republicanismo em 1817, que estava à espreita desde a Guerra dos Mascates, durando o regime por três meses. Esmagados pelas forças baseadas no Rio de Janeiro, os revoltosos tinham como alvo as capitanias do nordeste ${ }^{57}$, das quais apenas Paraíba e Alagoas aderiram. Mesmo com vida curta, essa fagulha de revolução demonstrou um certo senso de regionalismo. Certamente não tão vigoroso como nas treze ex-colônias, que chegavam a se considerar como soberanas individualmente, pois, de fato, a adstringente administração portuguesa tratou o Brasil como se fosse um monólito em termos políticos. Ainda assim, a maneira brasileira de experimentar a identidade como uma dicotomia de empatias nacionais e regionais moldou a futura federação. Tal percepção é primordial para o presente estudo comparado.

\footnotetext{
${ }^{56}$ LOWI, GINSBERG, supra n 46 , p. 27.

57 "The antipathy between the Brazilians and Portuguese in the area continued unabated from the days of the War of Mascates. A certain regional pride was involved in the conspiracy, which limited planning to the establishment of a republic only in the Northeast” BURNS, supra n 31, p.99.
} 
Quando a assembléia liberal que substituiu os comandantes de Napoleão reuniu-se em Portugal, o Brasil se viu ameaçado de perder o status de Reino Unido. A resposta da imprensa brasileira foi dada em uníssono. Em vez de se realçar a importância do consentimento das assembléias provinciais, foi enfatizada a "sanção da nação"58. De fato, o Brasil seguiu o caminho inverso dos Estados Unidos para se chegar uma federação. No caso norte-americano, uma nação teve de ser consolidada em vista da necessidade de unificar todas as entidades políticas enquanto que o senso de uma nação brasileira já estava há muito se estabelecendo. Além disso, a aristocracia rural não tendia a simpatizar com um federalismo descentralizado, demonstrando outra diferença de relevo com relação à Constituição americana. Ao contrário da elite no norte, a elite brasileira pensava que, se uma província almejasse estar separada da nação, teria de expressar a sua vontade ${ }^{59}$. Em outras palavras, a presunção era a de que todas as províncias haviam já aceito a existência de um governo central, o que não demandava a sua aquiescência expressa para a legitimação de tal governo. Considerando que nos Estados Unidos a legitimação desse governo central se deu num processo de muita barganha e discussão política, é de se notar essa diferença central na comparação dos dois processos de federalização.

Outra distinção digna de nota é que, passada a independência, a Constituição, virtualmente imposta por Dom Pedro I em 1824, não foi desenhada para conter princípios federalistas. Muito pelo contrário, a primeira Carta Magna do Brasil era a de um regime monárquico absolutista disfarçado sob um manto liberal. A camuflagem não era completa por conta dos artigos do título quinto, que prescreviam um outro ramo de poder além dos outros três comumente aceitos na doutrina de Montesquieu. O conhecido Poder Moderador era prerrogativa do Imperador, sendo que ele detinha também o Poder Executivo, e basicamente o tornava o árbitro final de todas as decisões tomadas no âmbito do legislativo e do judiciário ${ }^{60}$. Dadas as circunstâncias voláteis do Império, parece difícil explicar porque

\footnotetext{
${ }^{58}$ Idem, p. 108.

${ }^{59}$ Symptomatic of that sentiment is the declaration of a deputy from Ceará: "The Supreme Arbiter of empires created Brazil as a single territory from the Amazon to the Plata, and consequently it must never be divided without the very express and solemn declaration of those provinces which intend to separate themselves from the Brazilian union" in idem, p. 113.

60 "(...) the emperor exercised the functions of the chief executive but even more important than that he was the moderating power, an office which made him responsible for the maintenance of the independence of the nation as well as the equilibrium and harmony of the other powers and the twenty provinces. He enjoyed a veto over all legislation as well as the right to convoke or dissolve the General Assembly. (...) He could pardon criminals and review judicial decisions” Idem , p. 115.
} 
essa Constituição foi a que mais durou entre as sete que o Brasil já adotou. Numa tentativa breve de explicar esse fenômeno, pode se argüir que a elite rural estava alinhada com o plano de independência que não significasse uma mudança revolucionária na estrutura centralizada de poder deixada pelos portugueses. Tudo que os fazendeiros mais influentes queriam era substituir as antigas autoridades portuguesas ${ }^{61}$. Por óbvio, a arbitrariedade de Dom Pedro I derrubou as possibilidades de realização do desejo da oligarquia, mas apenas temporariamente. Em menos de 10 anos a contar da sua coroação, o imperador abdicava do trono. Seu filho, Dom Pedro II, ao conquistar a maioridade foi sábio o suficiente para não fazer uso do Poder Moderador e permitiu que a elite conservadora agrária ficasse à frente das questões governamentais até a queda da monarquia em 1889.

Talvez a monarquia tivesse durado por mais tempo se o modelo político houvesse provido uma economia bem sucedida. Os preços declinantes dos principais produtos agrícolas, sendo o café o mais importante no século XIX, conduziu o esquema imperial à bancarrota. Ressentido da falta de desenvolvimento industrial, Felisbelo Freire, um delegado do Estado de Sergipe na convenção que elaborava a primeira constituição federalista, rememorava os tempos coloniais para evidenciar a contínua e prejudicial política centralizada que trouxe vantagens apenas para os produtores rurais ${ }^{62}$. À beira do século XX, o Brasil tendia a um movimento de descentralização sem precedentes.

Como demonstrado pela experiência histórica de ambos países ora examinados, o tópico da tributação é o ponto de partida para mudanças constitucionais profundas. Ao mesmo passo que os colonos ingleses se revoltaram contra a imposição de tributos nos anos que se seguiram em 1760, a emergente elite política urbana desgostava do sistema centralizado de tributação e de distribuição de receita. Para os vários delegados brasileiros presentes na convenção que resultou na Constituição de 1891, a fraqueza e a miséria encontradas em diversas províncias era o resultado da constante drenagem de recursos locais em favor da coroa. Em verdade, os artigos 15, inciso 10, e 36, inciso 1, da Constituição imperial alocava a maior parte da competência orçamentária no legislativo

\footnotetext{
61 "Conservative by nature, they (the planter aristocrats) supported no structural reforms. The only change they sought was to substitute themselves for the Portuguese in power" Idem, p. 110.

62 "[The] decree of January, 1785, which extinguished all existent factories in Brazil, shows us the obstacle that the metropolitan government raised against industrial organization, being the public power an inertial factor in which our economic life has developed in three centuries" FREIRE, Felisbelo, História Constitucional da República dos Estados Unidos do Brasil, Ed. Universidade de Brasília, Brasília, 1983.
} 
nacional, que, não por acaso, era composto de proprietários de terras, tendo em vista que tanto o sufrágio como o direito de ser eleito dependiam de requisitos baseados em patrimônio. Essa competência era exercida ao seu máximo, praticamente excluindo financeiramente as assembléias provinciais ${ }^{63}$.

O parênteses necessário a ser posto nessa situação, em que as províncias são fracas e pobres, é que a centralização não significava a ausência de poder local. A esse respeito, o Brasil havia herdado uma característica comum a toda América Hispânica, o “caudilho”, cujo surgimento se deu na era colonial. O latifundiário, conhecido como “coronel” nos domínios brasileiros, tradicionalmente exercia uma abrangente influência política na área que circundava suas imensas propriedades. Detinha trânsito não apenas nos três poderes, como também contava com suporte religioso, que fazia com que o povo venerasse a figura do coronel. Colhendo subsídios nos escritos de Schneider, segue uma concisa, mas esclarecedora, explicação do surgimento e desenvolvimento do coronelismo:

"Na ausência de um exército permanente de significância, todos os grandes proprietários eram obrigados a manter milícias privadas que recrutavam empregados e familiares. Com o tempo, tais milícias evoluíram para pequenas unidades organizadas de um exército particular sob o controle do mais poderoso entre as figuras regionais, que usualmente detinha a patente de coronel (originalmente, capitãomor). Tais coronéis eram responsáveis não só por manter a lei e a ordem no interior, mas também por certas funções governamentais, tendo em vista a ausência de autoridades oficiais nas áreas mais isoladas „64.

Logicamente, quando a convenção republicana decidiu pelo federalismo descentralizado, amplos poderes se transferiam para as mãos dos coronéis. É importante ressaltar que essa transferência de poderes é primordial para entender o resultado político da revolução de 1930, que vem a mudar o sistema federal concebido em 1891.

Diretamente inspirada pelo federalismo americano, a Constituição de 1891, inevitavelmente, continha similaridades com sua correspondente nos

\footnotetext{
63 "The manner how the revenue was distributed among provinces and the center (...) resulted in the impoverishment in which we arrived and created the subjective condition of the people aspiring for a political organization more open to the autonomy of small governments and their legitimate liberal aspirations" Idem, p. 108.

${ }^{64}$ SCHNEIDER, supra n 43, p. 27-28.
} 
Estados Unidos. No artigo sexto, foi introduzida a regra de não-intervenção a não ser que houvesse consentimento do Estado interessado ou desobediência a decisão de tribunal federal. A doutrina dos poderes expressos também havia sido importada juntamente com a cláusula “elástica” para o artigo 34, incisos 33 e 34. Pela primeira vez, as entidades locais poderiam legislar autonomamente a respeito de tributos, sendo o imposto sobre comércio interestadual a principal fonte de receita do tesouro estadual. Além disso, o legislativo passou a ser representado por duas casas, mas nada similar ao Three-Fifths Compromise foi sequer pleiteado uma vez que a escravatura havia sido abolida. O processo de emenda à constituição fugia do padrão de similitude com o corresponde norte-americano uma vez que era centralizado, não sendo necessário o consentimento dos Estados para mudanças do texto. Teoricamente, todos os poderes concedidos às diversas unidades políticas poderiam ser retirado pelo centro com uma emenda constitucional. Na prática, como será visto, o processo de emenda não foi utilizado para resolver uma necessidade social de re-centralização. Quando o tempo chegou, uma nova constituição teve de ser apresentada.

\section{A Experiência Federalista}

\subsection{Uma Centralização Gradual}

É possível afirmar que a recém-nascida federação norte-americana, com um produto da vontade de unidades soberanas de facto, se constituiu já numa entidade descentralizada. No entanto, a passagem do tempo demonstrou o conflito premente entre as esferas de poder federal e estadual. A confrontação entre a doutrina dos poderes expressos e a cláusula “elástica” caracterizaria um processo de centralização gradual de poder nos Estados Unidos.

Uma das primeiras grandes questões nacionais logo após a independência era, naturalmente, dívida pública gerada a partir da respectiva guerra. O recém empossado Secretário do Tesouro, Alexander Hamilton, planejou que o governo nacional assumisse as dívidas de cada Estado. Para alcançar este propósito, ele 
propôs a criação de um banco federal. Claramente, os Estados menos endividados eram contra essa medida. Alguns dos defensores da doutrina dos poderes expressos, entre eles Thomas Jefferson, argüiam que o projeto de Hamilton era inconstitucional já que o rol das competências federais não incluía a faculdade de se criar um banco ${ }^{65}$. Ao fim, o projeto passou sob o fundamento de que o banco era necessário para capacitar o governo federal no exercício de seu poder de coletar tributos, o que estava no espírito flexibilizador da cláusula “elástica”. No entanto, assim que o banco entrou em operação vários Estados passaram a tributálo, impondo um ônus extra ao seu funcionamento. O conflito chegou à Suprema Corte, onde se concluiu que os Estados não tinham autoridade para exigir impostos de agências federais ${ }^{66}$, o que ratificava a visão de Hamilton a respeito da constitucionalidade do banco ${ }^{67}$.

A eventual expansão territorial trouxe fricções outras entre os Estado e o centro político, embora suas implicações jurídicas parecessem mais amenas. Sob a constituição prévia, o governo confederado, em uma das suas poucas realizações, conseguiu convencer os entes confederados a desistir de seus pleitos territoriais, passando o território do noroeste a ser propriedade da confederação. Uma provisão dos Artigos prescrevia os modos como colônias nessa nova área poderia evoluir para Estados autônomos ${ }^{68}$. A federação que substituiu o sistema confederado herdou esse quadro jurídico. Como conseqüência, três outros Estados foram admitidos ao fim do século XVIII: Vermont, Kentucky e Tennessee. Com a proliferação de entes federados, logicamente a influência de cada Estado na esfera federal tendia a diminuir, o que causou insatisfação de certos segmentos políticos nas unidades mais antigas de New England. A disputa entre as duas esferas políticas se

\footnotetext{
65 "Hamilton's bank bill produced the most heated debates. Madison, Jefferson, Randolph, and others argued that because the Constitution made no provision for a national bank (or for Congress's issuing of articles of incorporation), Congress had no authority to create one" BRINKLEY, supra n 19, p. 159-160.

66 "Writing for the Court, Chief Justice John Marshall ruled that states had no power to tax national agencies” LOWI, GINSBERG, supra n 46, p. 25.

67 "The case involved the question whether Congress had the power to charter a national bank, since such a explicit grant of power was nowhere to be found in Article I, Section 8. Chief Justice John Marshall answered that the power could be 'implied' from other powers that were expressly delegated to Congress, such as the 'powers to lay and collect taxes, to borrow money, to regulate commerce; and to declare and conduct war" Idem, p. 46.

68 "The Ordinance of 1784, based on a proposal by Thomas Jefferson, divided the Western Territory into ten self-governing districts, each of which could petition Congress for statehood when its population equalled the number of free inhabitants of the smallest existing state” BRINKLEY, supra n 19, p. 138.
} 
agravaria com a compra do território da Lousiana, pertencente à França de Napoleão, pelos Estados Unidos em 1803. Questionou-se a competência do Executivo federal em aquisição de território. Sob o fundamento da cláusula "elástica”, mesmo que a faculdade não estivesse arrolada expressamente nas seções do artigo II da Constituição, a barganha entre Thomas Jefferson e Napoleão seria legítima porque estaria implícita no poder presidencial de celebrar tratados ${ }^{69}$. Em seguida, o sentimento de revolta de extremistas de New England chega ao ponto de se pregar a secessão com o intuito de formar uma Confederação do Norte $^{70}$. Entretanto, a rebelião nunca tomou corpo na realidade, e a sua ausência legitimou tacitamente a política federal de expansão para o ocidente e a criação de novos Estados. É de se pensar que o alargamento da União enfraqueceria a autoridade federal, mas na realidade o expansionismo territorial coincidia com uma projeção do poder central. É sintomático disso o fato de que era o governo federal encarregado de estabelecer as primeiras instituições nos novos entes federados, além de manter as políticas necessárias até que o Estado pudesse seguir seu próprio caminho.

Um problema não resolvido em 1787, a escravidão, fez com as engrenagens da guerra entrassem em funcionamento na década de 1860 entre o Norte e o Sul. A derrota dos confederados do Sul introduziram as emendas constitucionais XIII, XIV e XV. Os novos dispositivos restringiram a liberdade dos Estados em tolerar o trabalho escravo e ampliaram o devido processo legal e o direito de sufrágio aos negros ${ }^{71}$. Futuramente, a emenda subsequente estabeleceu a prerrogativa federal em tributar a renda dos indivíduos. Tal inovação viria a fortalecer a capacidade financeira do centro tendo em vista que o imposto de renda se tornou a principal fonte de receita pública, não apenas nos Estados Unidos, mas também mundo afora.

Mesmo com todos esses ganhos, a influência federal continuou a ser limitada quando comparada com as amplas funções governamentais dos Estados. Uma interpretação

\footnotetext{
69 "Jefferson's advisers persuaded him that his treaty-making power under the Constitution would justify the purchase of Louisiana; and Congress promptly approved the treaty and appropriated money to implement it" Idem, p. 188.

70 "Some New England Federalists raged against it. They realized that the more the West grew and the more new states joined the Union, the less power the Federalists and their region would retain. In Massachusetts, a group of the most extreme Federalists, known as the Essex Junto, concluded that the only recourse for New England was to secede from the Union and form a separate "Northern Confederacy" Idem, p. 189.

71 "Some New England Federalists raged against it. They realized that the more the West grew and the more new states joined the Union, the less power the Federalists and their region would retain. In Massachusetts, a
} 
restritiva do termo “comércio interestadual”, área de competência do Congresso Nacional, impediu que o poder central se manifestasse com relação a emergentes temas jurídicos como previdência social, anti-truste, transações financeiras, relações trabalhistas e regulações sanitárias. Contudo, quando condições socio-econômicas deterioram nos anos de 1930, e governança centralizada era necessária ${ }^{72}$, a Suprema Corte desistiu da antiga e rígida definição de "comércio interestadual”73 e o poder federal recebeu a maior parcela de competência sobre os ramos jurídicos que surgiam.

Com a passagem do século XX, naturalmente, a burocracia federal se desenvolveu e se especializou de maneira que talvez nem os fundadores do federalismo norte-americano teriam previsto. Entretanto, como Lowi e Ginsberg mostram graficamente ${ }^{74}$ a porção de competências atribuídas aos Estados ainda é muito significante. Além disso, desde o governo Reagan vem evoluindo um federalismo cooperativo, no qual os Estados têm a oportunidade de lidar com áreas que, na virada do século XIX para o XX, foram prontamente absorvidas pelo governo federal ${ }^{75}$. Essa tendência é possível porque no sistema está enraizada a crença na autonomia local em contraposição com a autoridade central. Essa filosofia parece ser a perene contribuição dos constituintes de 1787.

\subsection{Um Federalismo Pendular}

Em 114 anos de República, a problemática história constitucional brasileira vivenciou o impacto da disputa entre tendências centralizantes e descentralizantes. A frágil economia, especialmente sensível a flutuações no mercado internacional, e a instabilidade social dificultavam a formação de um ambiente político favorável à continuidade

group of the most extreme Federalists, known as the Essex Junto, concluded that the only recourse for New England was to secede from the Union and form a separate "Northern Confederacy" Idem, p. 189.

72 "The New Deal quite properly represented a recognition that the states could not go it alone, at least not after the US Supreme Court had so limited their powers that reform was stymied unless Congress acted" ELAZAR, Daniel J, Opening the Third Century of American Federalism, in KINCAID, John, The Annals of the American Academy of Political and Social Science, vol. 509, May 1990, p. 20.

73 "All this changed after 1937, when the Supreme Court threw out the old distinction between interstate and intrastate commerce, converting the commerce clause from a source of limitations to a source of power" LOWI, GINSBERG, supra n 46, p. 49.

${ }_{75}^{74}$ Idem, p. 45.

75 "The Reagan administration, (...) by shifting federal government priorities, reorganizing existing grant programs, and reducing federal domestic expenditures as a proportion of the total federal budget, it did succeed in introducing new attitudes among state and local officials and their constituents" ELAZAR, supra n 72, p. 16. 
constitucional. De 1889 até hoje, seis constituições, todas elas de natureza federal, foram adotadas. Cada uma tinha sua concepção de federalismo, dependendo das demandas sociais, políticas e econômicas.

A primeira fase da experiência federativa brasileira, vista por Celina Souza como a marca de um federalismo isolado, estendeu-se até 1930, quando Vargas já havia começado a fazer alterações por si próprio. O termo “isolado” é bem empregado já que os Estados passaram a exercer funções governamentais, mas sem interação nenhuma com o centro. De uma certa maneira, é possível pensar que houve uma radicalização dos princípios federalistas nesse primeiro momento. Tal separação extremista entre as duas esferas trouxe à tona o coronelismo, discutido acima, e um aprofundamento do desequilíbrio entre as unidades da federação.

Sob a luz da primeira Constituição, a política nacional havia se tornado uma questão de conflitos regionais. Usando seus vastos recursos sobre a respectiva área de influência, os coronéis representaram importantes variáveis no jogo de alianças entre Estados. Desde fraude eleitoral até intimidação de eleitores, os expedientes à disposição dos latifundiários eram a chave para a liderança estadual e assim para o poder nacional. Em certo ponto, contudo, as disputas locais ameaçavam a redução do Congresso Nacional a um órgão inativo conforme a "Política dos Governadores" selada pelo presidente Campos Sales. Por esse instrumento, os dois mais poderosos e populosos Estados, São Paulo e Minas Gerais, acordavam em alternarem o exercício do poder federal ${ }^{76}$.

Essa dominação dual revelou que o federalismo isolado havia criado um sistema em que as unidades mais fortes prevaleciam. Na presença de dois grandes participantes, ambos decidiram unir forças. Naturalmente, o esquema funcionava em detrimento das demais unidades, que eram suprimidos da participação na divisão dos recursos nacionais ${ }^{77}$.

Por cerca de 40 anos, a elite rural se manteve no poder. A crise iminente, no

\footnotetext{
76 “(...) Sales sealed an agreement with the governors of São Paulo and Minas to minimize the effects of regional conflicts in Congress. This agreement became known as the política dos governadores, the 'governor's politics'. According to the agreement each of these two states would alternately govern Brazil" SOUZA, Celina, Constitutional Engineering in Brazil, St. Martin’s Press, New York, 1997, p. 26.

77 "Financial and economic resources were channeled to São Paulo and Minas, showing that the Brazilian federation was born under the aegis of the concentration of resources in a few states, thus institutionalizing the country's regional inequalities” Idem, p. 27.
} 
entanto, era inevitável. A depreciação do café e de outros produtos rurais no mercado internacional levou o país ao caos econômico. Além disso, a ruptura da Política dos Governadores por São Paulo, que desejava eleger seu representante à presidência na vez de Minas Gerais, viabilizou a revolução.

A ascensão de Getúlio Vargas em 1930 marcou indubitavelmente a forma como o federalismo é percebido pela elite política brasileira. Um resoluto defensor da centralização como a cura política para a enfermidade contraída pelo regime anterior, Vargas implementou vorazmente sua ideologia antes mesmo que uma constituição o legitimasse. Por exemplo, para erradicar a corrupção na máquina eleitoral presente nos Estados, ele editou um Código Eleitoral de cunho federal em 1932 antes do sufrágio marcado para o estabelecimento da Assembléia Constituinte ${ }^{78}$. Em suas provisões, havia o voto secreto, como maneira de amenizar o problema da coerção no meio rural, e a criação de um braço eleitoral no Poder Judiciário federal, cujo objetivo inicial era expurgar as fraudes executadas pelos coronéis.

Uma das medidas de Vargas com relação à dívida pública assemelhou-se muito aos passos tomados pelos Estados Unidos logo após a aprovação da Constituição de 1776. Como o desastre financeiro se aproximasse para muitos Estados, inclusive São Paulo, por conta da inexperiência em gestão de recursos públicos, o ditador realizou a incorporação das dívidas dos Estados às do governo federal. Essa medida representou o abandono do federalismo isolado agudo, havendo agora uma divisão do ônus entre as unidades ${ }^{79}$.

Todas essas medidas tomaram forma constitucional mais tarde. Após a breve passagem da Constituição de 1934, marcada pela influência de Weimar, Vargas conseguiu se manter no poder e impôs sua própria versão de carta política em 1937. Os efeitos centralizantes desse documento são avassaladores. O escopo da intervenção federal foi ampliado, além de haver previsão de que Estados inadimplentes poderiam ser

\footnotetext{
78 "The new Electoral Code, issued in 1932, was followed by a decree, setting the year of 1933 as the date for elections of the constitutional convention" SKIDMORE, Thomas, Brasil; De Getúlio a Castelo, Paz e Terra, Rio de Janeiro, 1982.

79 "One of Vargas's first measures was to write off the states' debt to the federal government, including São Paulo enormous debt to sustain the value of coffee, therefore pacifying regional discontents" SOUZA, supra n 76, p. 27.
} 
transformados em Territórios Federais ${ }^{80}$. Em adendo, os tributos de competência dos entes federados foram eliminados e o imposto de renda, como aconteceu nos Estados Unidos, foi adotado como uma das principais fontes de receita federal conforme o artigo 20 (I) (c).

Por fim, a depressão econômica que varreu o globo e a necessidade de interferência governamental adicionaram novos tópicos, como relações trabalhistas e regulação de mercado, à competência da União. Já foi visto que o mesmo fenômeno também tomou lugar nos Estados Unidos, mas no Brasil a motivação teve como ponto primordial o desejo por industrialização. Assim, a implementação de empresas públicas no nível federal, com seus monopólios substanciais, minou ainda mais a capacidade política das autoridades regionais.

A política de Vargas, embora implementada de maneira autoritária, ajudou a alavancar os primeiros esforços de industrialização. Apesar disso, sua queda era inevitável ao fim da Segunda Guerra Mundial já que a democracia era prioridade na agenda nacional. A entrada de um regime democrático, contudo, não reverteria o processo centralizador promovido em 15 anos de revisão da traumática experiência do federalismo isolado ${ }^{81}$.

A quinta Constituição brasileira tendia à descentralização, como poderia se esperar, mas o modus operandi se assemelhava mais a um federalismo cooperativo em que a repartição de receita entre as duas esferas de poder tencionava transferir mais responsabilidades aos Estados, sem que a União perdesse suas prerrogativas de tributação. No entanto, o regime se viu uma vez mais ameaçado pela instabilidade econômica, agravada pelo conflito ideológico entre capitalismo e comunismo. Em 1964, o golpe militar pôs fim à tentativa de descentralização política. Sendo governados por uma ditadura repressiva, os Estados tiveram seus canais de influência bloqueados pela suspensão dos direitos políticos. Os militares avocaram para si a responsabilidade pelas questões fiscais, à semelhança de Vargas, justificando o ato na irresponsável administração dos recursos

\footnotetext{
80 "For intergovernmental relations the constitution reflected Vargas's attempt to achieve federal hegemony. (...) a state unable over three years to finance its services should be transformed into a 'territory'” Idem, p. 29.

81 “The New State [Vargas's dictatorial rule over Brazil] brought irreversible change to the political and bureaucratic institutions. More important than that, Vargas transformed the relationship between federal and state powers and, with this, put Brazil much more closer to a truly national government" SKIDMORE, supra n 78, p. 55.
} 
utilizados pelos Estados durante o breve regime democrático ${ }^{82}$. Para inaugurar uma outra fase industrial no Brasil e implementar o modelo econômico de substituição de importações, os governos militares buscaram soluções baseadas em medidas que partiam do centro para as unidades. Sob a Constituição de 1967, o país, de fato, chegava a dar a aparência de um Estado unitário disfarçado de uma federação ${ }^{83}$.

Finalmente, graças novamente ao declínio econômico, com a crise da dívida de 1980, o quadro constitucional seria transformado outra vez. A Constituição de 1988, seguindo o padrão pendular, concedeu aos Estados a relativa autonomia que lhes fora tirada tanto por Vargas como pelos militares. Entretanto, manteve algumas das contribuições da experiência dos anos 30. Por exemplo, embora não haja a possibilidade de transformar um Estado em Território Federal por questões de inadimplência, o rol de possibilidades de intervenção federal forçada compreende situações em que os Estados se encontram em dificuldades fiscais.

Para concluir o presente ponto, mais dois pontos merecem ser realçados para completar o estudo comparativo. Primeiramente, é importante notar que o processo de emenda constitucional sempre prescindiu do consenso direto dos Estados ao contrário do que acontece nos Estados Unidos. Considerando que cerca de 40 emendas foram aprovadas num período de 15 anos, a prerrogativa exclusiva do poder federal em alterar o texto constitucional demonstra a facilidade da União em conduzir a política nacional. No caso americano, como visto, as emendas devem passar pelo crivo das unidades federadas.

Em segundo lugar, o poder para legislar das assembléias estaduais em ambos países foi sempre desproporcional. Mesmo na fase mais radical de descentralização do federalismo brasileiro, os Estados, por exemplo, não detinham autoridade para legislar em ramos jurídicos clássicos como o Direito Civil, Comercial e Penal. Historicamente, toda a legislação respectiva foi importada de Portugal, na forma das Ordenações Reais, na medida em que os colonos não se importavam em aplicar um corpo estrangeiro de leis às suas disputas. Em adendo, como já foi verificado, a metrópole mostrou que sabia como efetivar os seus regulamentos no território da colônia. De fato, as ordenações portuguesas estavam

\footnotetext{
82 "The argument supporting fiscal centralization was that the earlier commitment to collective responsibility, through shared powers with Congress, and to the amelioration of conditions of poverty, through social policy and populist rhetoric, had led to unrestrained public spending" SOUZA, supra n 76, p. 32.

${ }^{83}$ SELCHER, W., A New Start Toward a More Decentralized Federalism in Brazil?, in Publius: The Journal of Federalism 19 (Summer), p. 169
} 
em vigor no Brasil até 1917, quando o Código Civil de Bevilácqua foi finalmente editado. O resultado é que a legislação brasileira é em grande parte federal, sendo o contrário facilmente observável nos Estados Unidos.

\section{Conclusão}

A análise histórica revela as principais diferenças entre as duas federações desde que consideradas como instituições contínuas. Em suma, as distinções de relevo são duas. Para começar, em seu nascedouro, a federação norte-americana era composta de entes que se consideravam plenamente autônomos desde a independência da Inglaterra. Não seria exagerado afirmar que as ex-colônias americanas eram entidades soberanas de fato. A decisão de se incorporarem a uma federação implicou na transferência de poder existente para um novo corpo político. O movimento contrário se observa no Brasil. Uma vez que a resolução de se tornar uma federação foi tomada, o processo de transição operou-se de uma autoridade central poderosa para unidades inexperientes e despreparadas. Isso vem a explicar o fenômeno em que uma federação mais descentralizada se denota nos Estados Unidos enquanto o Brasil vacila em movimentos pendulares de concentração e desconcentração.

A segunda grande diferença pode ser observada no período que se seguiu após a adoção do federalismo em cada país. O sistema americano mostrou-se mais adaptável que o brasileiro, sendo este marcado por rupturas não absorvidas pelo sistema político. Se considerarmos que a transmissão de poder do centro para as unidades é um processo mais difícil de se alcançar, a segunda distinção é conseqüência da primeira. Independentemente disso, é certo que o federalismo está em evolução em ambos países. Afinal de contas, a era do federalismo isolado brasileiro, por exemplo, havia deixado suas marcas indeléveis e lições valiosas com relação à espinhosa transfusão de poder experimentada nos primórdios da república. Tentar legitimar unidades políticas desiguais na formação de um governo coletivo, sem a manutenção de uma autoridade central capaz de harmonizar os recursos disponíveis, é tarefa infrutífera. Em certa medida, o Brasil demonstrou aprender com as 
experiências, ganhando o reconhecimento do seu federalismo robusto quando comparado a outras nações latino-americanas ${ }^{84}$.

Por fim, a escolha de sistemas federais parece inescapável tanto para os Estados Unidos como para o Brasil. Os gigantes continentais não teriam outra escolha, tendo em vista os inúmeros contrastes regionais próprios de um território extenso e regularmente povoado. No caso brasileiro, mesmo quando o sistema "balança", um compromisso com o federalismo persiste:

"Apesar do balanço do pêndulo federal, o federalismo permaneceu um compromisso constitucional, uma ideologia política e um mecanismo de negociação política num país de dimensões territoriais vastas e com disparidades regionais. "85

\section{Referências}

ABREU, João Capistrano de. Chapters of Brazil’s colonial history: 1500-1800. New York: Oxford University, 1997.

BRINKLEY, Alan. The unfinished nation. New York: McGraw-Hill, 1993.

BROGAN, Hugh. Longman history of the United States of America. New York: Longman, 1986.

BURNS, E. Bradford. A history of Brazil. New York: Columbia University, 1970.

ELAZAR, Daniel J. Opening the third century of american federalism. The Annals of the American Academy of Political and Social Science, v. 509, may 1990.

84 “Brazil has long been a case of the most robust federalism in Latin America” MAINWARING, Scott, Presidentialism in Brazil: the Impact of Strong Constitutional Powers, Weak Partisan Powers, and Robust Federalism, Latin American Program, Woodrow Wilson International Center for Scholars, n 25, p. 27.

${ }^{85}$ SOUZA, supra n 76, p. 33. 
FREIRE, Felisbelo. História constitucional da República dos Estados Unidos do Brasil. Brasília: Universidade de Brasília, 1983.

FURTADO, Celso. The economic growth of Brazil. Westport: Greenwood, 1984.

KAMMEN, Michael. People of paradox. New York: Oxford University, 1980.

LOWI, J. Lowi; GINSBERG, Benjamin. American government. 7th ed. Norton: W.W., 2002.

MADISON, James. et al. The federalist papers. London: Penguin, 1987.

MAINWARING, Scott. Presidentialism in Brazil: The Impact of Strong Constitutional Powers, Weak Partisan Powers and Robust Federalism. Washington, D.C.: Woodrow Wilson International Center, 1997.

McKAY, David. Essentials of american government. Boulder: Westview, 2000.

SCHNEIDER, Ronald M. Order and progress: a political history of Brazil. Boulder: Westview, 1991.

SELCHER, W. A new start toward a more decentralized federalism in Brazil? Publius: The Journal of Federalism, v. 19, summer [1989?].

SKIDMORE, Thomas. Brasil: de Getúlio a Castelo. Rio de Janeiro: Paz e Terra, 1982.

SOUZA, Celina. Constitutional engineering in Brazil. New York: St. Martin’s, 1997.

US STATE DEPARTMENT. Outline in American History. Disponível em: $<$ http://usinfo.state.gov/products/pubs/history/toc.htm.>.

WILLIAMSON, Edwin. The penguin history of Latin America. London: Penguin, 1992. 